\title{
Contamination of Pasteurized Fruit Juices with Bacillus licheniformis in West Azerbaijan Province, Iran
}

Farid Soltani (MSc)

Department of Food Engineering, Maragheh Branch, Islamic Azad University, Maragheh, Iran

Saman Mahdavi (PhD)

Department of Microbiology, Maragheh Branch, Islamic Azad University, Maragheh, Iran

Corresponding author: Saman Mahdavi

Email: S.mahdavi@iau-maragheh.ac.ir Tel: +98-9144150454

Address: Department of

Microbiology, Maragheh Branch, Islamic Azad University, Maragheh, Iran

Received: 29 May 2018

Revised: 02 Aug 2018

Accepted: 04 Aug 2018

\section{ABSTRAC'T}

Background and objectives: Bacillus licheniformis is a potential cause of spoilage in pasteurized products. The aim of this study was to identify and isolate $B$. licheniformis from commercial pasteurized fruit juices distributed in the West Azarbaijan Province, Iran.

Methods: Sixteen fruit juice samples including four apple juice and 12 orange juice samples were collected from five fruit juice manufacturing companies in Iran. The samples were tested for the presence of $\boldsymbol{B}$. licheniformis by culture in specific media and biochemical testing. Suspected samples were also investigated for the presence of the bacterium by polymerase chain reaction using specific primer for the gyrß gene.

Results: Three samples (18.75\%) from the 16 tested fruit juice samples were found as positive. In other words, one apple juice sample (25\%) and two orange juice samples (16.66\%) were contaminated with B. licheniformis.

Conclusion: Isolation of this bacterium indicates the unsuitable manufacturing conditions and ineffective bacterial decontamination, which might also be favorable for the growth of other fruit juice spoilage bacteria.

KEYWORDS: Bacillus licheniformis, Fruit and Vegetable Juices, Polymerase Chain Reaction. 


\section{INTRODUCTION}

Pasteurization of non-alcoholic drinks with acidity of $<4$ is conducted at temperature of $65{ }^{\circ} \mathrm{C}$ for 15 minutes (1). In Iran, the pasteurization of fruit juice is commonly performed at $70-75{ }^{\circ} \mathrm{C}$ for 20 minutes. Thus, only bacteria that are resistant to heat and acidity can survive in the fruit juice after the pasteurization process. Among the Bacillus species, spores of Bacillus licheniformis can resist high temperatures up to $135^{\circ} \mathrm{C}(2,3)$. This soil-borne bacterium is able to grow at $13-60{ }^{\circ} \mathrm{C}$ and spreads quickly in the culture medium. In industry, it is used for protease production, which is highly important for the production of laundry detergents (4). Important alkaline proteases such as subtilisin BPN and subtilisin carlsberg are also produced from this bacterium (5). Furthermore, $B$. licheniformis is used for controlling some plant diseases, such as mango-related diseases and gray mold of apples $(6,7)$. This important food-borne pathogen (8) is also a potential source of spoilage in pasteurized foods, particularly in milk (9). The Environmental Conservation Organizations in the United States do not consider this bacterium as a human pathogen (10). However, there are reports on the potential production of toxins by $B$. licheniformis in cases of food poisoning (11). It has been revealed that the bacterium also has the potential to produce considerable amounts of enterotoxin, which could cause vomiting (12). The purpose of this study was to identify and isolate $B$. licheniformis from commercial pasteurized fruit juices distributed in the West Azerbaijan Province, Iran.

\section{MATERIAL AND METHODS}

We collected four apple juice samples and 12 orange juice samples from five Iranian fruit juice manufacturing companies that distributed products in the West Azerbaijan Province. After sterilizing the cap of fruit juice containers by alcohol, $0.5 \mathrm{ml}$ of the fruit juice was cultured on potato dexterose agar (containing cycloheximide to inhibit the growth of mold and yeast) and orange serum agar. The culture media were incubated at 45 ${ }^{\circ} \mathrm{C}$ for 3-5 days. To provide axenic culture conditions, the colonies appearing on the culture media were streaked on orange serum agar. Later, several biochemical tests were performed to identify $B$. licheniformis (13). B. licheniformis PTCC1320 was used as the positive control.

\section{DNA extraction}

DNA was extracted from $B$. licheniformis strains cultured in brain heart infusion medium (Merck Co., Germany) using PGEX 2050 kits (Pak gene Yakhteh Company, Iran, Catalog No: PGEX 3050).

\section{Detection of gyrB gene by polymerase chain reaction (PCR)}

Specific primers were designed using the primer-BLAST software, and PCR was performed in a solution with final volume of $20 \mu \mathrm{l}$, containing $10 \mu \mathrm{l}$ of sterile deionized water, $2 \mu \mathrm{l}$ of $10 \mathrm{X}$ PCR buffer, $0.6 \mu \mathrm{l}$ of $\mathrm{MgCl}_{2}, 0.4 \mu \mathrm{l}$ of dNTPs, $0.4 \mu \mathrm{l}$ of each specific primers (Table 1), 1.6 unit of Taq DNA polymerase and $6 \mu$ l of extracted DNA. Cycling conditions were as follows: primary denaturation at $94{ }^{\circ} \mathrm{C}$ for 5 minutes, 35 cycles of denaturation at $94{ }^{\circ} \mathrm{C}$ for 50 seconds, annealing at $58.5^{\circ} \mathrm{C}$ for 58 seconds, extension at $72{ }^{\circ} \mathrm{C}$ for 1 minute and a final extension cycle at $72{ }^{\circ} \mathrm{C}$ for 7 minutes.

PCR products were electrophoresed on $1.5 \%$ agarose gel and then photographed using a Gel Doc system. DNA extracted from $B$. licheniformis PTCC 1320 was used as the positive control. Deionized distilled water was used as the negative control. Samples containing the $g y r B$ gene (by presence of a 118 bp fragment) were considered positive for $B$. licheniformis.

Table 1- Sequence of the specific primers used for the detection of the gyrB gene (14)

\begin{tabular}{ccc}
\hline Gene & Sequence & PCR product size (bp) \\
\hline gyrb & 5'-AAAGCTGATTTGAAAGTCATTGGAGAT-3' & 118 \\
& 5'-GAGTGGCGAGCGTATCATAGTC-3' & \\
\end{tabular}




\section{RESULTS}

Presence of $B$. licheniformis was confirmed in four samples, including an apple juice sample and three orange juice samples. Table 2 shows the results of the biochemical tests used for the detection of $B$. licheniformis in fruit juice samples.

After 24 hours of incubation at $43{ }^{\circ} \mathrm{C}$, the bacterium significantly spread on the orange serum agar and almost the whole surface of medium was occupied by the bacterial colonies. Although none of the tested samples were collected from expired products, all positive samples were related to juice containers with a swollen appearance before being opened. Among the four positive samples in the culture method, three samples $(18.75 \%)$ were identified as B. licheniformis in the PCR test (Figure 1). In other words, the results of PCR showed that one apple juice sample $(25 \%)$ and two orange juice samples $(16.66 \%)$ were contaminated with $B$. licheniformis.

Table 2- Results of the biochemical tests used for the detection of $\boldsymbol{B}$. licheniformis

\begin{tabular}{|c|c|c|c|c|c|c|c|c|c|c|c|c|c|c|}
\hline 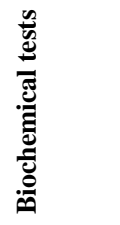 & 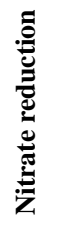 & 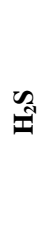 & $\begin{array}{l}\frac{0}{\frac{g}{g}} \\
\text { }\end{array}$ & 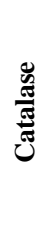 & 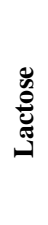 & 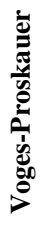 & 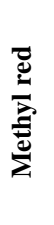 & 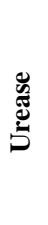 & 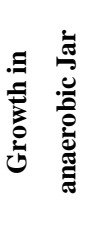 & $\begin{array}{l}0 \\
0 \\
0 \\
0 \\
0 \\
0 \\
0 \\
0 \\
0 \\
0\end{array}$ & 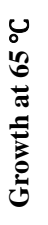 & 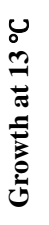 & 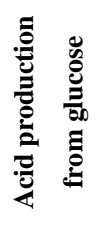 & 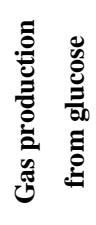 \\
\hline Results & + & - & - & + & & + & + & + & + & . & & & + & - \\
\hline
\end{tabular}

\begin{abstract}
Figure 1-Results of amplification of the gyrB gene for identification of samples positive for $B$. licheniformis. Production of the $118 \mathrm{bp}$ fragment confirms presence of the gyrB gene. Lane 1: DNA marker (50bp); lane 2: negative control (deionized distilled water); lane 3: positive control (B. licheniformis PTCC 1320); lanes 4,6 and 7: samples positive for $B$. licheniformis; lane 5: negative samples
\end{abstract}

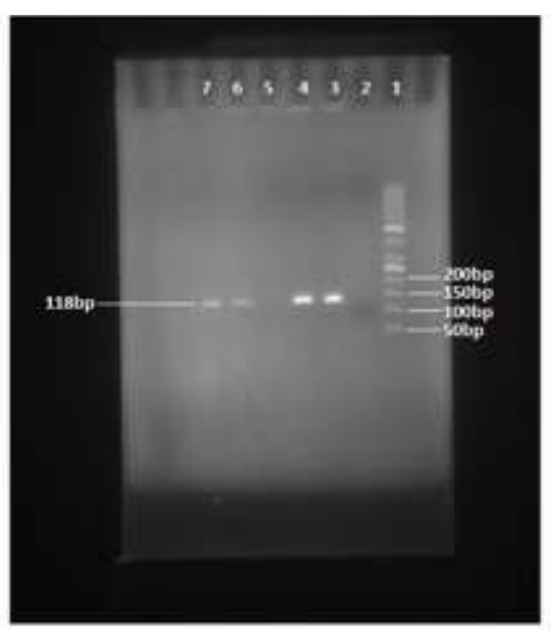

\section{DISCUSSION}

The sources of contamination of fruit juices with microorganisms include raw fruits, soil, birds, insects and contaminated instruments. The total count of microorganisms in a healthy fruit varies from 1000 to 1000000 per gram, and may be higher in damaged and moldy fruits. Proper washing of fruits reduces the level of primary contamination by up to $90 \%$ (15). This is the first study in Iran that has identified and isolated B. licheniformis in fruit juices based on a molecular method. We found that $25 \%$ of apple juice samples and $16.66 \%$ of orange juice samples were contaminated with
B. licheniformis. Overall, four samples $(18.75 \%)$ in our study were contaminated with the bacterium. Similar to our study, in a study by Motamedi and Tajbakhsh (2014), 12.5\% of commercial pasteurized orange juices tested were contaminated with $B$. licheniformis (16). Spores of $B$. licheniformis have also been isolated from carrot juice (17) and milk (18) samples. Sadeghi et al. (2015) found $B$. licheniformis contamination in $4 \%$ of traditional ice creams and $4.76 \%$ of handmade carrot and cantaloupe juices in Gorgan, Northeast of Iran (19). In this study, the gyrB gene was used for the molecular detection of 
B. licheniformis. The gene has been used for primer design and specific probing of the bacterium, with a favorable accuracy (20). In the culture method, four samples $(25 \%)$ under investigation were positive, while in the PCR method, three samples were positive for $B$. licheniformis. This demonstrates the high accuracy of the molecular technique compared to the culture methods. The contamination of pasteurized fruit juice with $B$. licheniformis indicates that other bacteria resistant to the pasteurization process can also survive and spoil the product if given the suitable conditions.

\section{CONCLUSION}

Bacterial contamination of fruit juice

\section{REFERENCES}

1. Yokota A, Fujii T, Goto K. Alicyclobacillus: Thermophilic Acidophilic Bacilli. Springer, Berlin, Germany. 2007; 35.

2. Simmonds P, Mossel BL, Intaraphan T, Deeth HC. Heat resistance of Bacillus spores when adhered to stainless steel and its relationship to spore hydrophobicity. J Food Prot. 2003; 66(11): 2070-5.

3. Janštová B, Lukášová J. Heat resistance of Bacillus spp. spores isolated from cow's milk and farm environment. Acta Vet Brno. 2001; 70(2): 179-84.

4. Bisset KA, STREET J. Morphological phases in the swarm of Bacillus licheniformis. J Gen Microbiol. 1973; 76(2): 369-73.

5. Falahatpisheh H, Jalali M, Badami N, Mardani N. Alkaline Protease Production and its Purification from a Soil Separated Alkalophilic Bacillus. J Rafsanjan Uni Med Sci. 2005; 4(4): 312-319.

6. Jamalizadeh M, Etebarian HR, Alizadeh A, Aminian $\mathrm{H}$. Biological control of gray mold on apple fruits byBacillus licheniformis (EN74-1). Phytoparasitica. 2008; 36(1): 23.

7. Silimela M, Korsten L. Evaluation of pre-harvest Bacillus licheniformis sprays to control mango fruit diseases. Crop Prot. 2007; 26(10): 1474-81.

8. Rowan NJ, Caldow G, Gemmell CG, Hunter IS. Production of diarrheal enterotoxins and other potential virulence factors by veterinary isolates of Bacillus species associated with nongastrointestinal infections. Appl Environ Microbiol. 2003; 69(4): 2372-6.

9. Zhou $\mathrm{G}$, Liu $\mathrm{H}$, He J, Yuan Y, Yuan Z. The occurrence of Bacillus cereus, B. thuringiensis and B. mycoides in Chinese pasteurized full fat milk. Int J Food Microbiol. $2008 ; \quad 121(2)$ : $195-200$. DOI:10.1016/j.ijfoodmicro.2007.11.028.

10. US Environmental Protection Agency. Bacillus licheniformis Final risk assessment. Biotechnology program under toxic substances control Act (TSCA). Available at: http://www.epa.gov/biotech_rule/pubs/fra/fra005.htm. $\underline{2009}$ could be due to various factors including the production environment, preservation time, transportation conditions, unsterile equipment and use of damaged containers. Therefore, ensuring the sanitary conditions in all these stages will dramatically reduce the possibility of microbial contamination of these products.

\section{ACKNOWLEDGMENTS}

This article has been derived from a thesis approved by the Islamic Azad University of Maragheh, Iran. The authors gratefully acknowledge cooperation of all participants in the study.

\section{CONFLICT OF INTEREST}

There is no conflict of interest.

11. Salkinoja-Salonen MS, Vuorio R, Andersson MA, Kämpfer P, Andersson MC, Honkanen-Buzalski T, et al. Toxigenic strains of Bacillus licheniformis related to food poisoning. Appl environ Microbiol. 1999; 65(10): 4637-45.

12. Pedersen PB, Bjørnvad ME, Rasmussen MD, Petersen JN. Cytotoxic potential of industrial strains of Bacillus sp. Regul Toxicol Pharmacol. 2002; 36(2): 15561.

13. Cowan ST, Steel KJ, Barrow GI, Feltham RKA. Cowan and Steel's manual. for the identification of medical bacteria. Cambridge University Press, London,U.K. 1993; pp:88.

14. Hu H, Zhao D, Zhang Q. Primers and probe design for identification and analysis of oil degradation bacteria (Bacillus licheniformis) with quantitative $P C R$ technology. Biotech. 2015; 14(4):194-9.

15. Institute of standards and industrial research of Iran. Soft drinks fruit juice and fruit juice products. Microbiological specification and test methods. 2012; No:3414

16. Motamedi H, TajBakhsh A. A report on pasteurized orange juice contamination with Bacillus licheniformis. $\mathrm{J}$ Food Microbiol. 2014; 1(1): 39-42.

17. Tola YB, Ramaswamy HS. Thermal destruction kinetics of Bacillus licheniformis spores in carrot juice extract as influenced by $\mathrm{pH}$, type of acidifying agent and heating method. LWT-Food Sci Technol. 2014; 56(1): 131-7.

18. Mansour M, Amri D, Bouttefroy A, Linder M, Milliere JB. Inhibition of Bacillus licheniformis spore growth in milk by nisin, monolaurin, and $\mathrm{pH}$ combinations. J Appl Microbiol. 1999; 86(2): 311-24.

19. Sadeghi M, Amini A, Arefian A, Behnampou N, Ghasemi SM. Microbiological quality of traditional ice cream and homemade juices in Gorgan and its relationship with health conditions of workers and environment. J Health Field. 2015; 2(4): 35-43.

20. Renouf V, Claisse O, Lonvaud-Funel A. rpoB gene: a target for identification of $L A B$ cocci by PCR-DGGE and melting curves analyses in real time PCR. J Microbiol Meth. 2006; 67(1): 162-70. 